This apparently close connection between solar prominences and magnetic storms perhaps explains why it is that the latter sometimes take place when there are no spots, or no very large spots on the solar surface. Thus, for instance, there may be prominences and magnetic storms when there are no spots; prominences may also sometimes $b$ ? associated with large spots, and as the latter can be seen while the former cannot, the resulting magnetic storm is generally attributed to the spots.

Further, the magnitude of magnetic storms appears to vary according to the particular position as to latitude of the prominence on the sun's disc. The nearer the poles (either north or south) the prominence occurs, and these are the regions where no spots exist, the greater the magnetic storm.

In conclusion, it may be stated that the inquiry has shown that the variations of the general magnetic phenomena, as given by Ellis, synchronise with the occurrence of prominences about the solar equator, while his " great " magnetic disturbances occur, in point of time, with the appearance of prominences in the polar regions of the sun. Prof. Bigelow has recently (L.S. Monthly Weather Review, July, 1902 , p. 352) investigated the variations in the horizontal magnetic force, and finds that the curve representing these changes exhibits subsidiary maxima which synchronise with those recorded in the curve representing the mean variation of prominences for all latitudes. Thus, to use his own words, "the remarkable synchronism between the curves cannot escape recognition, except after the year 1894 , when an extra minor crest is developed in the horizontal force."

Witlliam J. S. LOCKYER.

\section{THE FORTRESS OF THE MOLE.}

FOR the last three-quarters of a century, at any rate, natural history writers have been content to copy a diagrammatic figure of the breeding-hillock of the mole, without the least attempt to ascertain for themselves to what extent it is based on actual fact. The diagram in question was based on a fairly authentic account of the mole's habits drawn up by de Vaux just a century ago, but was elaborated by G. St. Hilaire and further "improved " by Blasius. Recently, Mr. L. E. Adams, whose special study is the Mollusca, has examined a large series of mole-hi!locks in Staffordshire and has found that in no case does the struc ture of the one in which the nest is formed correspond with the current diagram of the so-called "fortress." $\mathrm{Hi}$ account, illustrated with numerous diagrams (two of which we are enabled to reproduce) is published in vol. xlvii., No. 4 , of the Memoirs of the Manchester Literary and Philosophical Society. It shows that in certain other respects our ideas of the life-history of the mole require modification.

With regard to the situation of the breeding-hillock, or fortress, as it still may be conveniently called, Mr. Adams finds that this is generally in the open field, although it may uccasionally be placed in a hedge-bank, but only when there is a ditch alongside. Indeed, the proximity of water seems to be the main factor in determining the position of the structure. Now and then a fortress may be found under a tree, but it is considered by the author that such a position is probably accidental.

According to the old idea, it was supposed that the run with which it is permeated were made on a certain definite plan, allowing of free escape from the invasions of foes both above and below ground. This idea receives no support from the new observations, which tend to show that the more or less complicated galleries are purely incidental, and, with the exception of one "bolt-hole," have no reference to premeditated escape. In place, indeed, of being examples of a wonderful instinct of self-preservation on the part of their constructor, it appears that the galleries of the fortress are the natural, incidental and inevitable nutcome of the work of excavating the nest-cavity and piling up the superincumbent mound.

When the site for the fortress has been fixed, a circular cavity is excavated for the reception of the nest at a depth of from two to six inches below the surface of the ground, except in the case of bnggy soil or in situations liable to be flooded, when the nest is often made above the original NO. I 738 , vOL. 67$]$ ground-level. The easiest way to dispose of the excavated soil is to push it up to the surface, and for this purpose a tunnel is constructed, and in such a case the whole mound is made by this tunnel.

"When this superincumbent earth," writes the author, "has reached an inconvenient height, another tunnel is made, sometimes from another part of the nest-cavity (Fig. I, $a, b)$, but more often sideways from the first upward tunnel. All this takes time, and the mole meanwhile makes fresh runs from the fortress, the seat of its labour, in various

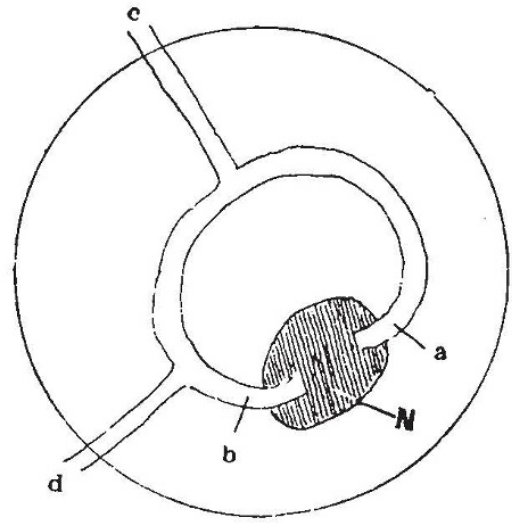

Fitg. 3.-Plan of a simple mole fortress, from above. $a, b$, excavation tunnels ; $c, d$, tunnels madc for forming protecting heap; $\mathrm{N}$, nest.

directions in search of food. Much of the earth displaced in making these fresh runs falls into the nest-cavity, and has to be disposed of in the same way as before, and also the soil displaced in making the bolt-run and the downshaft, when this latter occurs, Now the tunnel (or tunnels) leading upwards from the nest-cavity becomes larger and larger, winding round under the surface of the growing fortress. When this removal of earth becomes too fatiguing, on account of the length of the tunnel, the mole will often begin to make new tunnels from runs close to the end of the

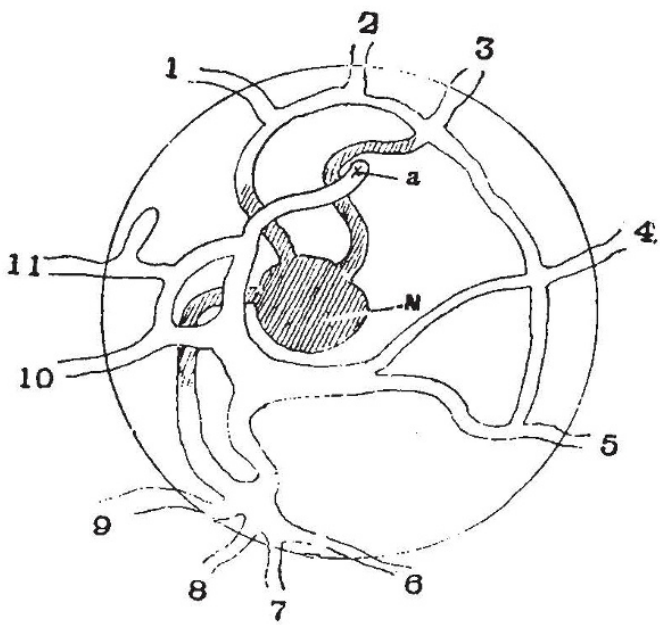

Fic: 2. - A complicated molefortress with eleven exits. a, apex of the tunnels; $\mathrm{N}$, nest.

fortress. Sometimes these new runs break into those leading from the nest-cavity, but not very often; usually they lie above them."

It thus appears that the tunnels are for two distinct purposes. First, we have those formed for ejecting earth from the nest-cavity and bolt-run, which are generally in the shape of a corkscrew ascending from the nest, and often with blind divergent terminations. And, secondly, lunnels 
unconnected with the nest-cavity, but traversing the fortress from external runs, through which earth has been carried to heap over the nest. Fig. 2 shows a fortress of the most complicated type.

Except when in marshy soil, nearly every fortress has the aforesaid bolt-run, which leads upwards from the bottom of the nest, and thus outwards, without connection with the other tunnels. More rarely a down-shaft, which may be nearly a yard in length, descends obliquely from the nest. The use of these down-shafts is not apparent. Presumably it is in them that the collections of paralysed worms, supposed to be stored up by the mole as food, have been found. Such collections of worms are, however, regarded by the author as accidental.

The nest-cavity, which is about the size of a large cottageloaf, and worn smooth by friction, contains a ball of grass or leaves, or a mixture of both, by which it is completely filled. In the case of the English species, at any rate, no fur from the mole's body is used in lining the nest. Apparently a nest is never used for more than one season, but two or even three nests, generally one above the other, may be found in the same fortress, of which the newest is alone in use. In all cases it appears that the female makes a fortress and nest of her own in which to breed, this being usually less complex than that of her partner, and without a bolt-run. Whether previous to the breeding-time the female inhabits the same fortress as the male is doubtful, and it is not improbable that moles are polyandrous.

It is now demonstrated that the female produces only a single litter annually. The young are usually born between the middle of April and the latter part of June, after a gestation of four weeks; the number in a litter varies from two to six, three or four being usual. The number of teats in the female is eight, and not, as usually stated, six.

R. L.

\section{THE VISIBILITY OF ULTRA-MICROSCOPIC PARTICLES.}

$\mathrm{I}$ the course of an optical investigation of various shades of ruby glass, Messrs. Siedentopf and Zsigmondy devised a method of observing small particles of gold which closely approach molecular dimensions, and thus extending our range of molecular vision very considerably.

The ruby glasses, examined by the best ordinary microscopes, appeared perfectly homogeneous. But the authors reasoned that if the gold particles embedded in the glass were at such distances apart that a microscope could resolve them, they could be made visible even though their size should be a small fraction of the wave-length of visible light. The only condition was that the product of the specific intensity into the surface of the luminous particles and the square of the sine of the effective angle of illumination should be greater than the inferior limit of the sensitiveness of the human eye. The problem is thus reduced to that of the visibility of a fixed star. What is seen is, of course, a diffraction disc, and that is all we can hope to see, but the authors indicate a means of determining the true size and weight of the particles seen.

It is essential that all disturbing side-lights should be avoided. The authors threw a beam of sunlight through a condenser on a slit 0.05 to $0.5 \mathrm{~mm}$. wide, and an image of the slit was produced in the field of vision by a telescope lens and a collimator with a reduction of 36 diameters. The diffraction discs seen in the ruby glass had an average apparent diameter of I mm., while their real diameter, calculated from the quantity of gold present and the number of particles counted in unit volume, was $0.02 \mu$. on the average. This gives a magnification of 50,000 diameters The utmost limit to which the magnification can be pushed by this method is about 150,000 diameters, or $6 \mu \mu$. The average diameter of a molecule being $0.6 \mu \mu$., it cannot be seen, even as a diffraction disc, unless its specific luminosity were ten times that of the solar molecules, or the sensitiveness of the eye were greatly increased. The cumulative effects used in photography may be resorted to, but the authors do not mention that possibility.

1 Abstract of a paper by $\mathrm{H}$. Siedentopf and R. Zsigmondy (Annalen der Physik, No. 1, 1903, pp. $\mathrm{x}-39$ ).

$$
\text { No. } 1738 \text {, vOL. } 67]
$$

\section{UNIVERSITY AND EDUCATIONAL INTELLIGENCE.}

OXFORD.-A meeting of the teachers of natural science was held in the examination schools last Saturday to hear the views of a deputation of the Association of Public School Science Masters on the subject of entrance scholarship examinations. It was agreed that two principal subjects should be offered in scholarship examinations, and a suggestion was made that the subjects should be selected from physics, chemistry, botany, zoology and geology. The meeting was divided in opinion as to whether botany and zoology should form one group or two. With regard to the recommendation of the deputation that candidates not offering chemistry and physics should be given an elementary paper in these subjects, the meeting was unanimous as to the desirability of this course, and further suggested the addition for those candidates of a practical examination in elementary, chemistry and physics, which should not be confined to qualitative analysis.

Cambridge.-At a conference held on rebruary 7 between representatives of the Association of Public School Science Masters and the college tutors in natural science, the following recommendations in regard to the college examinations for entrance scholarships and exhibitions were provisionally agreed to:-(I) That the science part of the examination should consist of: (I) Papers and practical work in not. more than six subjects, namely, (I) physics, (2) chemistry, (3) geology, (4) the natural history of plants, (5) zoology, (6) the elements of botany and zoology, it being understood that no candidate may take the subject (6) if he take either of the subjects (4) or (5). Of these six subjects candidates must offer not more than two. (2) Candidates who take subjects (3), (4), (5) or (6) should be required to take an elementary paper in physics and chemistry. (3) Candidates who take subject (I) should be required to take an elementary paper in mathematics.

The vacancy at Caius College, caused by the death of Dr. N. M. Ferrers, F.R.S., has been filled by the election of the Rev. E. S. Roberts, senior tutor to the mastership.

The Gilbey lecturer in agriculture will give this term a course of lectures on small holdings and allotments in the Chemical Theatre, on Fridays, at 5.

A REPORT of the Committee of Privy Council in favour of the petitions of the Liverpool University College and Owens College, Manchester, for charters of incorporation as independent universities, was submitted to the King in Council on Monday and approved by him. The decision will be received with pleasure by all who are interested in the development of higher education in this country. It is essential that we should have more universities if we are to march with the times. Regional universities are not known in any civilised country, and only end in examinations and the destruction of real teaching and research. In the report published in Tuesday's Times, the committee expresses the opinion that as the step involves issues of great moment, and as the effect of the multiplication of universities ought not to be lost sight of, the authorities of the Yorkshire College at Leeds should have the opportunity of submitting a draft charter incorporating a University in Yorkshire before the draft charters sought are finally settled, and that the institutions concerned should be invited to consider in greater detail not only the points on which joint action is desirable, but also the methods by which it can best be secured. The committee also considers that special rights of inspection should be reserved to the King as Visitor, and that careful provision should be made in the charters to secure an effective voice to external and independent examiners in all examinations for degrees.

DR. D. J. Cunningham, F.R.S., professor of anatomy in Dublin University, has been unanimously elected to succeed Sir William Turner in the chair of anatomy at Edinburgh.

REUTER reports that it has been decided to create a chair of commercial science, with a special faculty, in the University of Zurich, which is the first on the continent to establish such a chair. 